\title{
Motor outcomes in patients with advanced Parkinson's disease treated with levodopa/carbidopa intestinal gel in Italy: an interim analysis from the GREENFIELD observational study
}

\author{
Leonardo Lopiano $^{1}$ - Nicola Modugno ${ }^{2}$ - Pietro Marano $^{3} \cdot$ Mariachiara Sensi $^{4}$. \\ Giuseppe Meco ${ }^{5}$ Antonino Cannas ${ }^{6}$ - Graziano Gusmaroli ${ }^{7}$. Filippo Tamma ${ }^{8}$. \\ Francesca Mancini ${ }^{9} \cdot$ Rocco $_{\text {Quatrale }}{ }^{10}$ - Anna Maria Costanzo ${ }^{11} \cdot$ Giuliana Gualberti $^{11}$. \\ Gabriella Melzi $^{11} \cdot$ Umberto di Luzio Paparatti $^{11} \cdot$ Angelo Antonini $^{12}$
}

Received: 6 April 2016/Accepted: 5 July 2016/Published online: 15 July 2016

(c) The Author(s) 2016. This article is published with open access at Springerlink.com

\begin{abstract}
Several levodopa/carbidopa intestinal gel (LCIG) studies showed a significant reduction of OFF time and a significant increase of ON time, as well as a reduction of dyskinesia, and improvement of non-motor symptoms and quality of life. However, few studies have been conducted in a large population for more than 3 years. Interim outcomes from GREENFIELD observational study on a large Italian cohort of advanced PD patients who started LCIG in routine care between 2007 and 2014, still on treatment at the enrollment, are presented. Comparison
\end{abstract}

Gabriella Melzi

gabriella.melzi@abbvie.com

1 Department of Neuroscience, University of Torino, Torino, Italy

2 Neurology Department, IRCCS Neuromed, Pozzilli (IS), Italy

3 Neurorehabilitation Unit, Casa di Cura Villa dei Gerani, Catania, Italy

4 Neurology Unit, Hospital Sant'Anna, Ferrara, Italy

5 Department of Neurology and Psychiatry (Parkinson's Centre) and Research Centre of Social Diseases (CIMS), Sapienza University, Rome, Italy

6 Neurology Unit, Policlinico Universitario Monserrato, Cagliari, Italy

7 Neurology Unit, Ospedale degli Infermi, Biella, Italy

8 Neurology Unit, Miulli Hospital, Acquaviva delle Fonti (BA), Italy

9 Parkinson Disease and Movement Disorders Centre, Neurology Unit, S.Pio X Clinic, Milan, Italy

10 Neurology Unit, Hospital dell'Angelo, Mestre (VE), Italy

11 AbbVie Srl, Campoverde (LT), Italy

12 Parkinson and Movement Disorder Unit, IRCCS Hospital San Camillo, Venice, Italy between baseline (before LCIG start) and visit 1 (at enrollment) is reported. Primary endpoint was Unified Parkinson's Disease Rating Scale (UPDRS) IV Item 39; secondary endpoints were UPDRS I and II, as outcome of quality of life. Overall, 145 of 148 enrolled patients from 14 Movement Disorder Centers in Italy were evaluable with a mean LCIG treatment period of $1.38 \pm 1.66$ years at enrollment. Compared with baseline, the mean score regarding daily time spent in OFF (UPDRS IV Item 39) at visit 1 significantly decreased from $2.1 \pm 0.8$ to $0.9 \pm 0.7$ (57\% reduction vs baseline, $P<0.0001$ ); UPDRS IV improved by $39 \%(P<0.0001)$; scores for dyskinesia duration and disability were reduced by $28 \%$ $(1.8 \pm 1.0-1.3 \pm 0.9 ; P<0.0001)$ and $33 \%(1.5 \pm 1.1$ to $1.0 \pm 1.0 ; P<0.0001)$, respectively; and the scores for painful dyskinesia and early morning dystonia were reduced by $56 \%(0.9 \pm 1.0-0.4 \pm 0.7 ; P<0.0001)$ and $25 \%(0.4 \pm 0.5-0.3 \pm 0.5 ; P<0.001)$, respectively. The preliminary results of this interim analysis support the efficacy of LCIG on motor complications and activities of daily living.

Keywords Advanced Parkinson's disease - Levodopacarbidopa $\cdot$ Intestinal infusion $\cdot$ Motor symptoms · Quality of life $\cdot$ Routine patient care

\section{Introduction}

Parkinson's disease (PD) is a chronic, progressive neurodegenerative disorder characterized by motor impairments (tremor, rigidity, bradykinesia, and postural instability) [1]. Further features include non-motor symptoms, such as cognitive dysfunction, depression, and sleep disorders [1, 2], resulting in reduced quality of life [3] and 
negative effects on social interactions [3, 4]. Moreover, patients with PD have a progressive loss of autonomy, with a consequent impact on caregiver quality of life.

As the disease progresses, the response duration to levodopa shortens and the therapeutic window narrows, resulting in unpredictable fluctuations, with random and sudden "OFF" periods, as well as disabling dyskinesia, which exert a negative impact on the overall daily activities and quality of life [5]. Motor and non-motor symptoms reflect fluctuations in levodopa plasma concentrations due to the short half-life of levodopa and erratic absorption in relation with delayed gastric emptying [6].

Continuous dopaminergic drug delivery, obtained with the administration of intraduodenal levodopa/carbidopa intestinal gel (LCIG), has been shown to provide a more stable plasma concentration of levodopa in patients with non-optimal control of motor fluctuations [7]. A number of studies have shown that LCIG leads to a significant reduction of OFF time and a significant increase of ON time, as well as a reduction of dyskinesias [8-11]. In addition, improvements in non-motor symptoms-and quality of life-were observed [12, 13]. However, few studies have been conducted in a large population of patients with PD to assess the long-term outcome (over a period of $>2$ years) of treatment with LCIG $[14,15]$. Therefore, the aim of this observational study was to evaluate the clinical outcomes of a large Italian cohort of patients with advanced PD receiving LCIG in routine clinical care to evaluate the effects of therapy on both motor and non-motor symptoms and the related impact on patient quality of life and caregiver burden from the initiation of LCIG therapy over a maximum exposure period of up to 9 years. Here, we present the interim results on motor symptoms and Unified Parkinson's Disease Rating Scale (UPDRS) scores in this large cohort of patients with advanced PD.

\section{Patients and methods}

\section{Study design}

This observational study was conducted in 14 movement disorder centers throughout the Italian territory.

Treatment with LCIG was initiated in a routine patient care setting, according to the Summary of Product Characteristics, including the nasointestinal phase.

\section{Patient selection}

Consecutive patients with advanced PD and motor complications, who started LCIG infusion according to clinical practice between 2007 and 2014, were considered for enrollment into the study.
Inclusion criteria were being treated with LCIG, the presence of adequate information about the previous medical history and treatment, and the presence of at least one fulfilled scale or questionnaire among a selected list. Patients could be enrolled at any time after LCIG treatment initiation. Exclusion criteria were the presence of conditions that could have interfered with the long-term continuation of LCIG therapy at the physician's discretion.

Patients fulfilling inclusion criteria were enrolled in the study at visit 1 ; during this visit, patient history and retrospective clinical parameters referred to the previous conventional PD treatment, nasointestinal phase, and initiation of LCIG treatment via PEG-J were collected as baseline (BL) data. During the same visit, the current clinical parameters were also collected as Visit 1 data. For the analysis, BL was defined as the last available data collected prior to $\mathrm{NJ}$ tube positioning.

The study design included two patient populations: the retrospective population and the prospective population. The retrospective population includes all patients who had been receiving treatment with LCIG for $>1$ year and up to 7 years before the enrollment visit (visit 1), with available BL retrospective assessment data for $>1$ year. The prospective population includes all patients receiving treatment with LCIG for $<1$ year before the enrollment visit. Patients continuing with LCIG treatment for further 2 years after enrolment and with follow-up visits on yearly basis will be included in the final analysis. Here, we present the interim results on data collected at Visit 1 on the overall population.

The protocol of the study was approved by the Ethics Committee of each local health authority. Each patient provided informed consent. The study was conducted according to the International Conference on Harmonization Good Clinical Practices.

\section{Patient evaluation}

For the interim analysis at Visit 1 (enrolment), the following assessments were considered:

- BASELINE data, including demographic characteristics, medical history, previous PD treatments, nasointestinal phase, LCIG treatment doses, including the total daily dose of infusion at discharge from the hospital, the Hoehn and Yahr scale, and the UPDRS I, II, and IV if available.

- VISIT 1 data, including the LCIG treatment doses, Hoehn and Yahr scale, and the UPDRS I, II, and IV.

The primary endpoint of this study was the Item 39 of the UPDRS IV (percentage of waking day spent in OFF) at the last available follow-up compared with BL. For the interim analysis, the comparison between visit 1 
assessment and BL data was analysed, as described in the protocol.

Secondary effectiveness measures included UPDRS I total score (in ON and OFF conditions), and activities of daily living (ADL), as assessed by means of the UPDRS II (in ON and OFF conditions). Motor complications were assessed by means of the UPDRS IV total score and subitems for dyskinesia duration (Item 32), dyskinesia severity (Item 33), painful dyskinesia (Item 34), and early morning dystonia (Item 35). Safety data will be analysed at study closure, since they were collected from enrolment visit onward. For this reason, in this interim investigation, no adverse events have been included.

\section{Statistical analysis}

Quantitative variables were summarized using the number of non-missing observations, mean, standard deviation (SD), median, first and third quartile, minimum, and maximum. Categorical variables were summarized using frequency count and percentage distribution. Statistical significance was considered to be met when the rounded $P$ was less than $\leq 0.05$. Comparison between BL and the last follow-up values of all endpoints were performed using a Wilcoxon signed-rank test.

\section{Results}

The first patient was enrolled in November 2012; through July 2014, a total of 148 patients were included among the participating centers. Three subjects were excluded from the evaluable population, as they violated the inclusion/ exclusion criteria.

Demographic characteristics, medical history, occupational status, and PD features are summarized in Table 1. Economical and aids supports for patients supplied by the Italian Healthcare System are reported in Table 1. The mean age (mean \pm SD) of patients was $70.4 \pm 7.7$ years (with $79.3 \%$ of the population aged over 65 years), the mean duration of PD was $14.6 \pm 6.6$ years, and the mean time since the onset of motor fluctuations was $5.9 \pm 4.0$ years.

Previous antiparkinsonian medications before the initiation of LCIG infusion and the corresponding mean daily dosages are reported in Table 2. At the start of LCIG infusion, oral levodopa was the most commonly used antiparkinsonian medication $(96.6 \%$ of patients, at a mean daily dose of $812.17 \pm 409.9 \mathrm{mg}$ ), followed by dopamine agonists $(64.1 \%)$. The use of antiparkinsonian medications after LCIG initiation was largely reduced, as reported in Table 2. The primary reasons for the initiation of LCIG treatment were disabling OFF periods in 111 patients $(76.6 \%)$ and uncontrolled dyskinesia in 29 patients $(20 \%)$.
At visit 1, the mean LCIG duration was $1.38 \pm 1.66$ years; the mean duration of LCIG infusion per day was $13.55 \pm 3.05 \mathrm{~h}$ during daytime and was terminated at bedtime in all patients; and the infusion duration was similar at the discharge from the hospital after nasointestinal titration $(13.23 \pm 3.4 \mathrm{~h})$. The mean duration of LCIG treatment at the time of the enrollment in the study was $1.38 \pm 1.66$ years (median value 0.79 ), with $28 \%$ of the patients receiving LCIG infusion for at least 2 years (Table 1). The mean total continuous infusion dose at LCIG start was $3.34 \pm 1.22 \mathrm{ml} / \mathrm{h}$, remaining stable at visit $1(3.21 \pm 1.09 \mathrm{ml} / \mathrm{h})$. The average morning dose was $8.78 \pm 3.4 \mathrm{ml}$ at LCIG initiation and $9.08 \mathrm{ml}$ at visit 1 (including $3 \mathrm{ml}$ for filling the device). At LCIG initiation, a mean of $1.5 \pm 1.3$ extra bolus doses was administered to $95 \%$ of the patients, and this number remained constant at Visit 1 (1.6 \pm 1.2 , in $100 \%$ of the patients).

Compared with BL, the mean score for daily OFF time (UPDRS IV Item 39; assessed in $88 \%$ of the patients at visit 1) significantly decreased from $2.1 \pm 0.8$ to $0.9 \pm 0.7$, with a reduction of 1.2 points $(57 \%$ reduction compared with BL, $P<0.0001$; Fig. 1). Moreover, $74 \%$ of the patients at visit 1 showed an UPDRS IV Item 39 score ranged 0 or 1 (Fig. 2).

Baseline assessments of motor complications in patients receiving conventional $\mathrm{PD}$ treatment before the initiation of LCIG infusion were collected at visit 1 and are presented in Table 3.

Compared with BL, complications of therapy, as assessed by the UPDRS IV score and improved by $39 \%$ $(P<0.0001)$; the UPDRS IV Item 32 score for dyskinesia duration was reduced by $28 \% \quad(1.8 \pm 1.0-1.3 \pm 0.9$; $P<0.0001)$; the UPDRS IV Item 33 score for dyskinesia disability was reduced by $33 \%(1.5 \pm 1.1-1.0 \pm 1.0$; $P<0.0001)$; the UPDRS IV Item 34 score for painful dyskinesia was reduced by $56 \%(0.9 \pm 1.0-0.4 \pm 0.7$; $P<0.0001)$; and the UPDRS IV Item 35 score for early morning dystonia was reduced by $25 \%$ $(0.4 \pm 0.5-0.3 \pm 0.5 ; P<0.001$; Table 3$)$.

Regarding the efficacy measures commonly associated with cognitive function and quality of life in ADL, significant improvement was observed in UPDRS I and UPDRS II scores. Compared with BL, the mean change for UPDRS I was 1.3 points in OFF and 0.9 in ON ( -19 and $-20 \%$, respectively), while the mean change for UPDRS II was 3.7 points in OFF and 1.6 in ON (-13 and $-9 \%$, respectively; Table 3$)$.

\section{Discussion}

Here, we report results from the largest Italian cohort of patients with advanced PD treated with LCIG in routine clinical practice, with patients from 14 Movement Disorder 
Table 1 Demographic and clinical characteristics of the study population

\begin{tabular}{|c|c|c|}
\hline Parameter & Value & Range \\
\hline Demographics & $n=145$ & \\
\hline Mean \pm SD age, years & $70.4 \pm 7.7$ & $49-90$ \\
\hline \multicolumn{3}{|l|}{ Age } \\
\hline$<65$ years, $n(\%)$ & $30(20.7 \%)$ & \\
\hline$\geq 65$ years, $n(\%)$ & $115(79.3 \%)$ & \\
\hline Age $>70$ years, $n(\%)$ & $78(53.8 \%)$ & \\
\hline Females, $n(\%)$ & $72(49.7 \%)$ & \\
\hline Males, $n(\%)$ & $73(50.3 \%)$ & \\
\hline White race, $n(\%)$ & $144(99 \%)$ & \\
\hline Mean \pm SD height, $\mathrm{cm}$ & $164.4 \pm 8.5$ & $145-185$ \\
\hline \multicolumn{3}{|l|}{ Occupational status } \\
\hline Worker, $n(\%)$ & $5(3.4 \%)$ & \\
\hline Retired, $n(\%)$ & $116(80 \%)$ & \\
\hline Housekeeper, $n(\%)$ & $11(7.6 \%)$ & \\
\hline Unemployed, $n(\%)$ & $13(9 \%)$ & \\
\hline \multicolumn{3}{|l|}{ PD medical history } \\
\hline Mean \pm SD age at PD diagnosis, years & $55.7 \pm 0.77$ & \\
\hline Mean \pm SD PD duration at visit 1 , years & $14.61 \pm 6.58$ & $1.3-46.7$ \\
\hline Mean \pm SD time since onset of motor fluctuations at visit 1 , years $(n=143)$ & $5.9 \pm 4.0$ & $1-21$ \\
\hline \multicolumn{3}{|l|}{ LCIG duration at enrollment, $n(\%)$} \\
\hline$\leq 1$ year & $105(72.4 \%)$ & \\
\hline $1-3$ years & $19(13.1 \%)$ & \\
\hline$\geq 3$ years & $21(14.5 \%)$ & \\
\hline Previous antiparkinsonian treatments (before LCIG infusion) & $N(\%)$ & $\begin{array}{l}\text { Daily dose, } \\
\text { mean } \pm S D\end{array}$ \\
\hline Previous deep brain stimulation & $3(2.1 \%)$ & NA \\
\hline Apomorphine SC (pump) (mg) & $14(9.7 \%)$ & $86.29(46.38)$ \\
\hline Apomorphine stylo (mg) & $7(4.8 \%)$ & $6.5(10.6)$ \\
\hline Support by the NHS & $N(\%)$ & \\
\hline NHS payment because of PD & $101(69.7 \%)$ & \\
\hline Care family allowance & $81(55.9 \%)$ & \\
\hline Disability pension & $79(54.5 \%)$ & \\
\hline Use of aids supplied by NHS & $41(28.3 \%)$ & \\
\hline
\end{tabular}

$L C I G$ levodopa/carbidopa intestinal gel, NHS National Health Service, $P D$ Parkinson's disease, $S C$ subcutaneous, $S D$ standard deviation

Table 2 Use of antiparkinsonian medications before and during LCIG at visit 1 among the 145 evaluable patients

\begin{tabular}{|c|c|c|c|c|}
\hline \multirow[t]{2}{*}{ Antiparkinsonian medications } & \multicolumn{2}{|c|}{ Before LCIG start } & \multicolumn{2}{|l|}{ At visit 1} \\
\hline & $N(\%)$ & $\begin{array}{l}\text { Daily dose, } \\
\text { mean } \pm \text { SD }\end{array}$ & $N(\%)$ & $\begin{array}{l}\text { Daily dose, } \\
\text { mean } \pm \text { SD }\end{array}$ \\
\hline Oral levodopa (mg) & $140(96.6 \%)$ & $812.17 \pm 409.93$ & $\begin{array}{l}7(5 \%) \text {-during the day } \\
37(26 \%) \text {-at night }\end{array}$ & $\begin{array}{l}307.0 \pm 281.0 \text { during the day } \\
155.4 \pm 75.3 \text { at night }\end{array}$ \\
\hline Dopamine agonists (mg) & $93(64.1 \%)$ & $6.38 \pm 5.6$ & $44(30 \%)$ & $5.6 \pm 3.8$ \\
\hline COMT inhibitors (mg) & $64(44.1 \%)$ & $577.8 \pm 336.8$ & $17(12 \%)$ & $255.9 \pm 102.9$ \\
\hline MAO inhibitors (mg) & $21(14.5 \%)$ & $2.33 \pm 3.31$ & $5(3 \%)$ & $3.6 \pm 4.0$ \\
\hline Amantadine (mg) & $25(17.2 \%)$ & $190.6 \pm 112.6$ & $8(6 \%)$ & $237.5 \pm 91.6$ \\
\hline
\end{tabular}

COMT catechol-O-methyl transferase, MAO monoamine oxidase, $N A$ not available, $S D$ standard deviation 


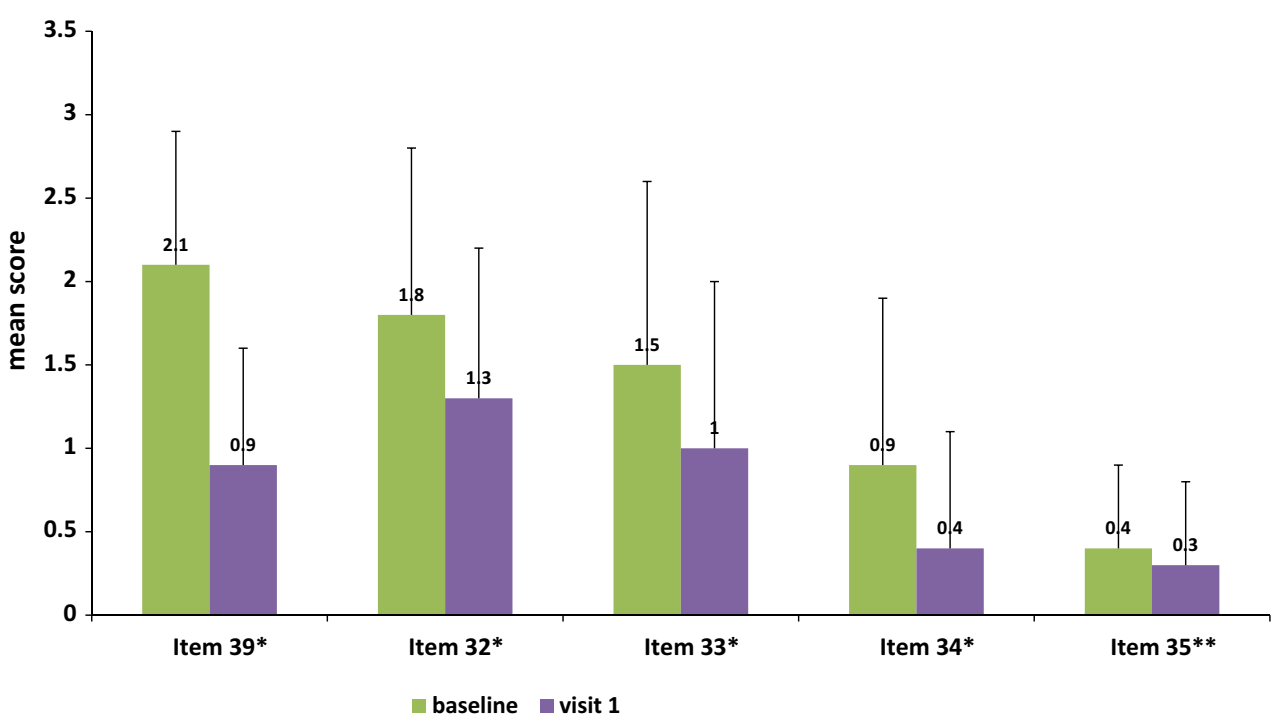

Fig. 1 UPDRS-Part IV mean subscores $\pm \mathrm{SD}$ at baseline (under conventional standard treatment) and at visit 1 (under LCIG treatment); asterisks represent statistical significance $(* P<0.0001)$,

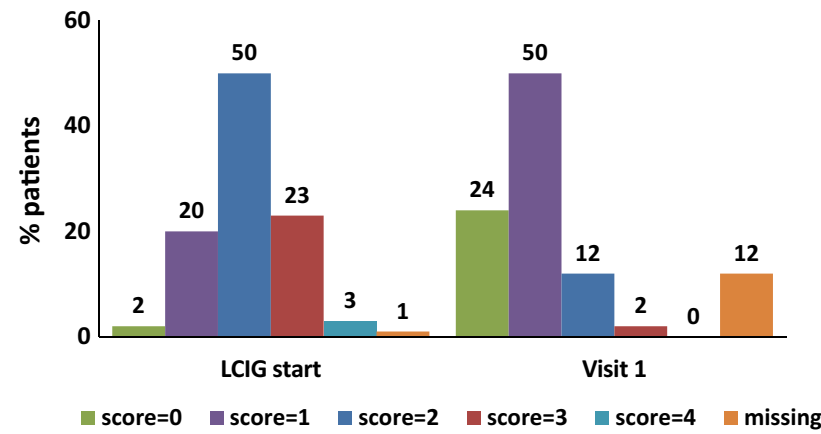

Fig. 2 Proportion of waking day spent in OFF state according to UPDRS-Part IV Item $39 \quad(0=$ none; $1=1-25 \%$ of day; $2=26-50 \%$ of day; $3=51-75 \%$ of day; $4=76-100 \%$ of day)

Centers. The population enrolled in this study was represented by advanced PD patients with motor fluctuations and dyskinesias not optimally controlled by conventional oral and transdermal treatments. The interim analysis showed a significant reduction in total daily OFF time after a mean of 1.4 years of LCIG use; the magnitude of improvement was consistent with the results reported in the previous studies [15-17]. Moreover, the high percentage of patients reporting a UPDRS item-39 score of 0 or 1 of Item 39 of the UPDRS IV (74\% of the cases) during LCIG infusion was clinically significant compared with the percentage reported under conventional treatments $(22 \%$ of the cases). The clinical relevance of this finding is further supported by the significant improvement of all the UPDRS IV items related to dyskinesias and the total score of UPDRS IV.
**P $=0.0002)$ compared to baseline from paired $t$ test. UPDRS Unified Parkinson's Disease Rating Scale

The results of the previous clinical studies on LCIG infusion have already indicated that this is an effective therapeutic strategy for improvements in motor symptoms (reduction in OFF time, increase in ON time without disabling dyskinesia, and reduction of troublesome dyskinesia) $[8,10]$, non-motor symptoms (somnolence, fatigue, cardiovascular, and urinary function) [12, 18-20], and quality of life. Recently, a 12-month interim analysis of an observational, routine care trial studying the long-term efficacy and safety of LCIG has shown significant reduction in mean daily $\mathrm{OFF}$ time $(-4.7 \mathrm{~h}$ vs BL) and $\mathrm{ON}$ time with dyskinesia $(-1.7 \mathrm{~h}$ vs BL), as well as a significant improvement in non-motor symptoms and quality of life [21].

Similarly, the improvements obtained in the UPDRS I and II for ADL were comparable to those reported in an international, 54-week, and open-label study in 354 patients with APD with $\geq 3 \mathrm{~h}$ per day of OFF time despite optimized therapy. In this study, the mean daily OFF time decreased by $4.4 \mathrm{~h}(65.6 \% ; P<0.001)$ and $\mathrm{ON}$ time without troublesome dyskinesia increased by $4.8 \mathrm{~h}$ (62.9\%; $P<0.001)$, while $\mathrm{ON}$ time with troublesome dyskinesia decreased by $0.4 \mathrm{~h}(22.5 \% ; P=0.023)$ [19].

Moreover, a recently published 12-week, randomized, controlled, double-blind, double-dummy trial in 71 patients with advanced PD whose motor complications were not adequately controlled ( $\geq 3 \mathrm{~h}$ /day OFF time) by the standard oral and transdermal therapy showed that LCIG produced $4.04 \mathrm{~h}$ of improvement in mean daily OFF time compared with BL and $1.91 \mathrm{~h}$ more than the improvement obtained with immediate-release oral levodopa-carbidopa (LC-IR) 
Table 3 Complications of therapy (UPDRS IV) at baseline (before LCIG treatment) and after a mean LCIG treatment period of $1.38 \pm 1.66$ years (visit 1 )

\begin{tabular}{|c|c|c|c|c|c|c|c|c|}
\hline & $\begin{array}{l}\text { BL } \\
\text { mean score }( \pm \text { SD })\end{array}$ & $N$ & Range & $\begin{array}{l}\text { Visit } 1 \\
\text { mean score }( \pm \mathrm{SD})\end{array}$ & $N$ & Range & $\begin{array}{l}\text { Reduction } \\
\text { vs BL (\%) }\end{array}$ & $P$ value \\
\hline UPDRS IV total score (items 32-42) & $8.5(3.4)$ & 138 & $0-18$ & $5.2(4.2)$ & 126 & $0-34$ & 39 & $<0.0001$ \\
\hline dyskinesia duration (item 32) & $1.8(1.0)$ & 142 & $0-4$ & $1.3(0.9)$ & 128 & $0-4$ & 28 & $<0.0001$ \\
\hline dyskinesia disability (item 33) & $1.5(1.1)$ & 141 & $0-4$ & $1.0(1.0)$ & 127 & $0-4$ & 33 & $<0.0001$ \\
\hline dyskinesia pain (item 34) & $0.9(1.0)$ & 141 & $0-4$ & $0.4(0.7)$ & 127 & $0-4$ & 56 & $<0.0001$ \\
\hline early morning dystonia (item 35) & $0.4(0.5)$ & 141 & $0-1$ & $0.3(0.5)$ & 128 & $0-1$ & 25 & 0.0002 \\
\hline OFF time duration (item 39) & $2.1(0.8)$ & 143 & $0-4$ & $0.9(0.7)$ & 128 & $0-3$ & 57 & $<0.0001$ \\
\hline \multicolumn{9}{|l|}{ UPDRS I total score } \\
\hline OFF & $6.9(4.7)$ & 87 & $0-16$ & $5.6(4.0)$ & 73 & $0-15$ & 19 & $<0.0001$ \\
\hline ON & $4.5(3.1)$ & 103 & $0-12$ & $3.6(2.8)$ & 121 & $0-12$ & 20 & 0.0191 \\
\hline \multicolumn{9}{|l|}{ UPDRS II (ADL) total score } \\
\hline OFF & $29.5(9.9)$ & 105 & $0-52$ & $25.8(10.2)$ & 82 & $3-50$ & 13 & $<0.0001$ \\
\hline ON & $18.6(9.5)$ & 118 & 0-39 & $17.0(8.9)$ & 126 & $0-44$ & 9 & 0.0033 \\
\hline \multicolumn{9}{|l|}{ UPDRS V (Hoehn and Yahr) total score } \\
\hline OFF & $4.0(0.8)$ & 128 & $2-5$ & $3.6(0.9)$ & 117 & $0-5$ & 10 & $<0.0001$ \\
\hline ON & $3.1(0.8)$ & 143 & $1-5$ & $2.8(0.8)$ & 145 & $1-5$ & 10 & $<0.0001$ \\
\hline
\end{tabular}

$A D L$ activities of daily living, $B L$ baseline, $L C I G$ levodopa/carbidopa intestinal gel, $S D$ standard deviation, UPDRS United Parkinson's Disease Rating Scale

treatment. In addition, an increase of $4.11 \mathrm{~h}$ in mean daily ON time without troublesome dyskinesia, corresponding to $1.86 \mathrm{~h}$ more than the improvement seen with LC-IR treatment (95\% CI $0.56-3.17 ; P=0.0059)$, was reported [22]. This beneficial effect has been confirmed in the 52 weeks open-label extension of this study on 62 patients suggesting that sustained improvement can be obtained with LCIG and that this benefit persists through 1 year of treatment [20]. This aspect is particularly relevant for LCIG long-term use, considering that due to the progressive nature of the disease, a conventional treatment could require frequent adjustments, while LCIG would represent a simplification of PD management in advanced stage.

Moreover, compared with previously published studies, recent reports in the literature cite an increase in the percentage of patients aged $<65$ years initiating LCIG therapy $[19,22]$. Indeed, age at treatment initiation is another important aspect in LCIG selection criteria consideration: in a prospective, open-label study in 28 patients with advanced PD treated with LCIG for a mean treatment period of 24 months, younger age at operation, and the absence or mild presence of psychiatric/behavioral symptoms were positive predictive factors in selecting the best candidates for LCIG therapy [16].

This is the first Italian study with data from a large population followed for a long period of time. Since this investigation is being conducted as an observational study, with the collection of data recorded during routine medical care, we consider these outcomes to be close to "real world" clinical practice. In general, these interim outcomes are consistent with those generated in controlled short-term clinical studies. The results reported here were derived from a mean treatment period of 14 months; clinical outcomes will be followed through 24 months of follow-up in this cohort of 145 patients with advanced PD to assess the benefits of LCIG infusion therapy for up to 9 years of treatment. The possible influence of treatment duration on the motor outcome and quality of life, as well as the subanalysis on retrospective and prospective arm, will be assessed at the end of the study.

A limitation of this interim presentation is that only data on motor complications and UPDRS II are currently available. Results on non-motor symptoms, axial symptoms, quality of life, and caregiver burden will be available in the final sample assessment. Another limitation of this study is the fact that the results are not corrected for the Levodopa Equivalent Daily Dose of concomitant oral/transdermal antiparkinsonian medications. The absence of interim data on adverse events associated with LCIG limits the ability to interpret the full benefit-risk profile in these patients and will be fully described in the final analyses.

In conclusion, these interim results confirm that treatment with LCIG produces clinically significant improvements on motor function in patients with motor symptoms not optimally controlled by oral/transdermal therapies. 
Acknowledgments The authors wish to acknowledge the other investigators from Italy who participated in this study in the collection of data: Deborah Lanni (Pozzili IS), Pamela Pastorello (Biella), Francesca Preda (Ferrara), Marco Vito Rossi (Acquaviva delle Fonti BA), Alfonso Rubino (Roma), Rossella Scatozza (Roma), Maria Rosaria Seminara (Catania), Paolo Solla (Cagliari), and Annarita Sorrentino (Mestre VE).

\section{Compliance with ethical standards}

Funding This work was funded by AbbVie Srl. AbbVie participated in the study design, research, data collection, analysis and interpretation of data, and writing, reviewing, and approving the publication.

Conflict of interest Angelo Antonini has received compensation for consultancy and speaker related activities from UCB, Boston Scientific, Boheringer Ingelheim, AbbVie, Zambon; he also received research support from Mundipharma, Neureca foundation, the Italian Ministry Research Grant RF-2010-2319551, and Horizon 2020 Program Grant No. 643706. He serves as consultant for BoheringerIngelheim for legal cases on pathological gambling. Antonino Cannas, Graziano Gusmaroli, Leonardo Lopiano, Francesca Mancini, Pietro Marano, Nicola Modugno, Rocco Quatrale, Mariachiara Sensi, and Filippo Tamma have received honoraria for consulting services and symposia from AbbVie. Anna Maria Costanzo, Giuliana Gualberti, Gabriella Melzi, and Umberto di Luzio Paparatti are employees of AbbVie Italy and may own AbbVie stocks/options. No further conflict of interest have been declared by authors.

Open Access This article is distributed under the terms of the Creative Commons Attribution 4.0 International License (http://crea tivecommons.org/licenses/by/4.0/), which permits unrestricted use, distribution, and reproduction in any medium, provided you give appropriate credit to the original author(s) and the source, provide a link to the Creative Commons license, and indicate if changes were made.

\section{The GREENFIELD study investigators}

Paolo Barone (Salerno), Annarita Bentivoglio (Roma), Antonino Cannas (Cagliari), Roberto Eleopra (Udine), Graziano Gusmaroli (Biella), Leonardo Lopiano (Torino), Francesca Mancini (Milano), Pietro Marano (Catania), Giuseppe Meco (Roma), Nicola Modugno (Pozzilli-IS), Claudio Pacchetti (Pavia), Rocco Quatrale (Mestre VE), Mariachiara Sensi (Ferrara), and Filippo Tamma (Acquaviva delle Fonti BA).

\section{References}

1. Martinez-Martin P, Rodriguez-Blazquez C, Forjaz MJ (2012) Quality of life and burden in caregivers for patients with Parkinson's disease: concepts, assessment and related factors. Expert Rev Pharmacoecon Outcomes Res 12(2):221-230

2. Chaudhuri KR, Healy DG, Schapira AH (2006) Non-motor symptoms of Parkinson's disease: diagnosis and management. Lancet Neurol 5(3):235-245

3. Ozdilek B, Gunal DI (2012) Motor and non-motor symptoms in Turkish patients with Parkinson's disease affecting family caregiver burden and quality of life. J Neuropsych Clin Neurosc $24: 478-483$

4. Schrag A, Hovris A, Moreley D, Quinn N, Jahanshahi M (2006) Caregiver-burden in parkinson's disease is closely associated with psychiatric symptoms, falls, and disability. Park Rel Disord 12:35-41

5. Fabbrini G, Brotchie JM, Grandas F, Nomoto M, Goetz CG (2007) Levodopa induced dyskinesias. Mov Disord 22:1379-1389

6. Nyholm D, Lennernas H, Gomes-Trolin C, Aquilonius SM (2002) Levodopa pharmacokinetics and motor performance during activities of daily living in patients with Parkinson's disease on individual drugs combinations. Clin Neuropharmacol 25:89-96

7. Nyholm D, Odin P, Johansson A, Chatamra K, Locke C, Dutta S, Othman AA (2013) Pharmacokinetics of levodopa, carbidopa, and 3-O-methyldopa following 16-h jejunal infusion of levodopacarbidopa intestinal gel in advanced Parkinson's disease patients. AAPS J 15:316-323

8. Abbruzzese G, Barone P, Bonuccelli U, Lopiano L, Antonini A (2012) Continuous intestinal infusion of levodopa/carbidopa in advanced Parkinson's disease: efficacy, safety and patient selection. Funct Neurol 27(3):147-154

9. Antonini A, Odin P, Lopiano L, Tomantschger V, Pacchetti C, Pickut B, Gasser UE, Calandrella D, Mancini F, Zibetti M, Minafra B, Bertaina I, De Deyn P, Cras C, Wolf E, Spielberger S, Poewe W (2013) Effect and safety of duodenal levodopa infusion in advanced Parkinson's disease: a retrospective multicenter outcome assessment in patient routine care. J Neural Transm 120:1553-1558

10. Antonini A, Fung VSC, Boyd JT, Slevin JT, Hall C, Chatamra K, Eaton S, Benesh JA (2016) Effect of levodopa-carbidopa intestinal gel on dyskinesia in advanced Parkinson's Disease patients. Mov Disord. doi:10.1002/mds. 26528

11. Eggert K, Schrader C, Hahn M, Stamelou M, Russmann A, Dengler R, Oertel W, Odin P (2008) Continuous jejunal levodopa infusion in patients with advanced Parkinson disease: practical aspects and outcome of motor and non-motor complications. Clin Neuropharmacol 31:151-166

12. Honig H, Antonini A, Martinez-Martin P, Forgacs I, Faye GC, Fox T, Fox K, Mancini F, Canesi M, Odin P, Chauduri KR (2009) Intrajejunal levodopa infusion in Parkinson's disease. A pilot multicenter study of effects on non motor symptoms and quality of life. Mov Disord 24(10):1468-1474

13. Zibetti M, Rizzone M, Merola A, Angrisano S, Rizzi L, Montanaro E, Cicolin A, Lopiano L (2013) Sleep improvement with levodopa/carbidopa intestinal gel infusion in Parkinson disease. Acta Neurol Scand 127(5):e28-e32

14. Zibetti M, Merola A, Ricchi V, Marchisio A, Artusi CA, Rizzi L, Montanaro E, Reggio D, De Angelis C, Rizzone M, Lopiano L (2013) Long-term duodenal levodopa infusion in Parkinson's disease: a 3-year motor and cognitive follow-up study. J Neurol 260(1):105-114

15. Zibetti M, Merola A, Artusi CA, Rizzi L, Angrisano S, Reggio D, De Angelis C, Rizzone M, Lopiano L (2014) Levodopa/carbidopa intestinal gel infusion in advanced Parkinson's disease: a 7-year experience. Eur J Neurol 21(2):312-318

16. Sensi M, Preda F, Trevisani L, Contini E, Gragnaniello D, Capone JG, Sette E, Golfre-Andreasi N, Tugnoli V, Tola MR, Quatrale R (2014) Emerging issues on selection criteria of levodopa carbidopa infusion therapy: considerations on outcome of 28 consecutive patients. J Neural Transm 121(6):633-642

17. Calandrella D, Romito LM, Elia AE, Del Sorbo F, Bagella CF, Falsitta M, Albanese A (2015) Causes of withdrawal of duodenal levodopa infusion in advanced Parkinson disease. Neurology $84: 1669-1672$ 
18. Reddy P, Martinez-Martin P, Rizos A, Martin A, Faye GC, Forgacs I, Odin P, Antonini A, Chaudhuri KR (2012) Intrajejunal levodopa versus conventional therapy in Parkinson disease: motor and nonmotor effects. Clin Neuropharmacol 35(5):205-217

19. Fernandez HH, Standaert DG, Hauser RA, Lang AE, Fung VS, Klostermann F, Lew MF, Odin P, Steiger M, Yakupov EZ, Chouinard S, Suchowersky O, Dubow J, Hall CM, Chatamra K, Robieson WZ, Benesh JA, Espay AJ (2015) Levodopa-carbidopa intestinal gel in advanced Parkinson's disease: final 12-month, open-label results. Mov Disord 30(4):500-509

20. Slevin JT, Fernandez HH, Zadikoff C, Hall C, Eaton S, Dubow J, Chatamra K, Benesh J (2015) Long-term safety and maintenance of efficacy of Levodopa-Carbidopa intestinal gel: an open-label extension of the double-blind pivotal study in advanced Parkinson's disease patients. J Parkinsons Dis 5(1):165-174
21. Antonini A, Yegin A, Preda C, Bergmann L, Poewe W, On behalf of the GLORIA study investigators and coordinators (2015) Global long-term study on motor and non-motor symptoms and safety of levodopa-carbidopa intestinal gel in routine care of advanced Parkinson's disease patients; 12-month interim outcomes. Parkinsonism Relat Disord 21(3):231-235

22. Olanow CW, Kieburtz K, Odin P, Espay AJ, Standaert DG, Fernandez HH, Vanagunas A, Othman AA, Widnell KL, Robieson WZ, Pritchett Y, Chatamra K, Benesh J, Lenz RA, Antonini A, For the LCIG Horizon Study Group (2014) Continuous intrajejunal infusion of levodopa-carbidopa intestinal gel for patients with advanced Parkinson's disease: a randomised, controlled, double-blind, double-dummy study. Lancet Neurol 13(2):141-149 